\title{
An orally effective dihydropyrimidone (DHPM) analogue induces apoptosis-like cell death in clinical isolates of Leishmania donovani overexpressing pteridine reductase 1
}

\author{
Neeloo Singh • Jaspreet Kaur • Pranav Kumar • Swati Gupta • Nasib Singh • \\ Angana Ghosal • Avijit Dutta $\cdot$ Ashutosh Kumar • RamaPati Tripathi • \\ Mohammad Imran Siddiqi • Chitra Mandal • Anuradha Dube
}

Received: 22 May 2009 /Accepted: 30 June 2009 /Published online: 21 July 2009

(C) The Author(s) 2009. This article is published with open access at Springerlink.com

\begin{abstract}
The protozoan parasite Leishmania donovani is the causative agent of visceral leishmaniasis. The enzyme pteridine reductase 1 (PTR1) of $L$. donovani acts as a metabolic bypass for drugs targeting dihydrofolate reductase (DHFR); therefore, for successful antifolate chemotherapy to be developed against Leishmania, it must target both enzyme activities. Leishmania cells overexpressing PTR1 tagged at the N-terminal with green fluorescent protein were established to screen for proprietary dihydropyrimidone (DHPM) derivatives of DHFR specificity synthesised in our laboratory. A cell-permeable molecule with impressive antileishmanial in vitro and in vivo oral activity was identified. Structure activity relationship based
\end{abstract}

N. Singh $(\bowtie) \cdot$ J. Kaur $\cdot$ P. Kumar

Drug Target Discovery \& Development Division,

Central Drug Research Institute,

Lucknow 226001, India

e-mail: neeloo888@yahoo.com

S. Gupta $\cdot$ N. Singh $\cdot$ A. Dube

Division of Parasitology, Central Drug Research Institute,

Lucknow 226001, India

A. Kumar · M. I. Siddiqi

Division of Molecular and Structural Biology,

Central Drug Research Institute,

Lucknow 226001, India

R. Tripathi

Division of Medicinal and Process Chemistry,

Central Drug Research Institute,

Lucknow 226001, India

A. Ghosal $\cdot$ A. Dutta $\cdot$ C. Mandal

Department of Infectious Disease and Immunology,

Indian Institute of Chemical Biology,

Kolkata 700032, India on homology model drawn on our recombinant enzyme established the highly selective inhibition of the enzyme by this analogue. It was seen that the leishmanicidal effect of this analogue is triggered by programmed cell death mediated by the loss of plasma membrane integrity as detected by binding of annexin $\mathrm{V}$ and propidium iodide (PI), loss of mitochondrial membrane potential culminating in cell cycle arrest at the sub-G0/G1 phase and oligonucleosomal DNA fragmentation. Hence, this DHPM analogue [(4-fluoro-phenyl)-6-methyl-2-thioxo-1, 2, 3, 4tetrahydropyrimidine-5-carboxylic acid ethyl ester] is a potent antileishmanial agent that merits further pharmacological investigation.

\section{Introduction}

The kinetoplastid parasite Leishmania donovani is the causative agent of visceral leishmaniasis (VL) known as Kala-azar in India. Over $90 \%$ of VL cases occur in India, Bangladesh, Sudan, Brazil and Nepal (http://www.oneworldhealth.org/ diseases/leishmaniasis.php). The control of leishmaniasis in absence of vaccine solely depends on the choice of chemotherapy. Treatment available for VL is far from ideal (Berman et al. 2006; Sundar and Chatterjee 2006). The search for development of a new, safe, effective and inexpensive drug that can cure VL throughout the world continues. In the search for better therapeutics against VL, we focused on a validated drug target viz. folate biosynthetic pathway which is unique to the parasite (Bello et al. 1994). The enzyme pteridine reductase 1 (PTR1; accession no. AY547305) of $L$. donovani acts as a metabolic bypass for drugs targeting dihydrofolate reductase (DHFR); therefore, for successful antifolate chemo- 
therapy to be developed against Leishmania, it must target both enzyme activities. Reduced pterins and folates are essential for the growth of Leishmania parasites, but antipteridines have not shown much promise clinically against Leishmania in contrast to other protozoal infections (Hardy et al. 1997). This establishes the need for continued effort and research in this direction. Since dihydropyridines and pyrimidinones (80 thiones) are known inhibitors of DHFR and exhibit antitubercular activity against Mycobacterium tuberculosis, a pathogen residing in macrophages like Leishmania (Küçükgüzel et al. 2007), we were interested to see whether they exhibit any pteridine reductase inhibitory activities, and therefore, this study was undertaken. Dihydropyrimidone (DHPM) analogues have exhibited important therapeutic and pharmacological properties as the integral backbone of several calcium channel blockers (Kappe 2000), antihypertensive agents (Atwal et al. 1991), $\alpha$ la-antagonist (Kappe et al. 1997) and neuropeptide Y antagonists (Wang et al. 2006). A broad range of biological effects including antiviral, antitumor, antibacterial and anti-inflammatory activities have been described for these compounds (Kappe 1993). Further, understanding the mode of action and binding modes of these DHPM analogues to specific target sites may be used to design potent, novel, selective and less toxic antileishmanial analogues of these compounds on a structural basis. Here, we report a novel DHPM analogue that is cell permeable and a potent oral antileishmanial molecule in vivo. We also sought to determine the mechanism of leishmanicidal activity of this compound. There are several reports showing that Leishmania apoptosis occurs in response to antileishmanial drugs (Wang et al. 2006; Singh et al. 2005). It has also been demonstrated that the antileishmanial toxicity of trivalent antimonials is associated with apoptosis (Mann et al. 2006; Shaha 2006). This analogue induces programmed cell death (PCD) in Leishmania parasites via externalisation of phosphatidyl serine involving changes in mitochondrial membrane potential leading to DNA fragmentation.

\section{Materials and methods}

Materials M-199 medium and foetal bovine serum (FBS) were obtained from Gibco-BRL, dimethyl sulphoxide (DMSO) from SRL, ethanol from Merck, propidium iodide (PI), Annexin V-PE and MitoTracker deep red from Molecular Probes. All other chemicals were from Sigma unless stated.

Parasite culture Transgenic parasites overexpressing PTR1-green fluorescent protein (GFP chimaera, PTR1 tagged at the N-terminal with GFP) were cultured at $25^{\circ} \mathrm{C}$ in M-199 medium supplemented with 10\% heat-inactivated
FBS, $100 \mathrm{U}$ penicillin, $100 \mu \mathrm{g} / \mathrm{ml}$ streptomycin and in the presence of $150 \mu \mathrm{g} / \mathrm{ml}$ geneticin sulphate (G418; Kumar et al. 2007). These GFP-transfected parasites were used to determine the $\mathrm{IC}_{50}$ of the compound by flow cytometric analysis as established by us (Singh and Dube 2004). In vitro antileishmanial activity was expressed as $\mathrm{IC}_{50}$ which is the concentration that resulted in $50 \%$ inhibition of parasites (Kumar et al. 2008).

Candidate compound Compound [(4-fluoro-phenyl)-6methyl-2-thioxo-1,2,3,4-tetrahydropyrimidine-5-carboxylic acid ethyl ester] was prepared by our earlier reported method (Fig. 1; Dwivedi et al. 2005).

Cytotoxicity test upon cells The toxicity of compound was evaluated on non-activated, freshly isolated normal human peripheral blood mononuclear cells (PBMC) isolated according to standard protocol (Fuss et al. 2009). PBMC concentration was adjusted to $2 \times 10^{6}$ viable cells $/ \mathrm{ml}$ after estimation of viability by trypan blue exclusion assay. Viability was consistently greater than $96 \%$. Cells $\left(1 \times 10^{6}\right)$ were incubated with various concentrations of the compound at $37^{\circ} \mathrm{C}$ in $5 \% \mathrm{CO}_{2}$ for $24 \mathrm{~h}$. The mean percentage of post treatment viable cells relative to control was evaluated by epifluorescence microscopy (Leica) using Live-Dead Cell Staining Kit (BioVision).

Antileishmanial activity in vivo Syrian golden hamsters (Mesocricetus auratus) were infected intracardially with $1 \times 10^{7}$ amastigotes isolated from the spleen of heavily infected donor hamsters. Splenic biopsies were carried out on day 25 p.i. for assessing the status of infection by making spleen dab smears. Animals having ten to 15 amastigotes per 100 spleen cell nuclei were selected and used for screening purposes. Animals were treated orally with the compound at $12.5,25,50,75$ and $100 \mathrm{mg} / \mathrm{kg}$ dose for five consecutive days. Splenic biopsies were again performed on day 7 post treatment, and the parasite burden in treated and untreated group was quantitated. Percent

Fig. 1 Chemical structure of (4-fluoro-phenyl)-6-methyl-2thioxo- $1,2,3,4$ tetrahydropyrimidine-5carboxylic acid ethyl ester<smiles>CCCCCOC(=O)C1=C(C)NC(=S)NC1c1ccc(F)cc1</smiles> 
inhibition of parasite multiplication was calculated by the following formula:

$\mathrm{PI}=\frac{\mathrm{AT} \times 100}{\mathrm{IT} \times \mathrm{TI}}$

where PI is percent inhibition; AT is actual number of amastigotes per 100 spleen cell nuclei in treated animals; IT is initial number of amastigotes per 100 spleen cell nuclei in treated animals; and TI is times increase in untreated control animals. The use of animals for all the experiments was in compliance with the relevant guidelines of the institutional animal ethics committee.

DNA content (percent sub-G1) analysis by flow cytometry L. donovani promastigotes $\left(2 \times 10^{6} \log\right.$ phase $)$ overexpressing PTR1-GFP chimaera treated with compound $(98 \mu \mathrm{M}, 0-48 \mathrm{~h})$ were harvested by centrifugation at $2,000 \times g$, for $5 \mathrm{~min}$ at $4^{\circ} \mathrm{C}$. Cells were washed once in $1 \mathrm{ml}$ phosphate-buffered saline (PBS) and then fixed by incubation in $70 \%$ ethanol:30\% PBS for $1 \mathrm{~h}$ at $4{ }^{\circ} \mathrm{C}$. Prior to analysis, fixed cells were harvested by centrifugation at $1,000 \times g$, for $10 \mathrm{~min}$ at $4^{\circ} \mathrm{C}$, washed in $1 \mathrm{ml} \mathrm{PBS}$ and then resuspended in $1 \mathrm{ml}$ PBS with RNAse A $(100 \mu \mathrm{g} / \mathrm{ml})$ and PI at $10 \mathrm{mg} / \mathrm{ml}$. The cells were incubated at $25^{\circ} \mathrm{C}$ for $45 \mathrm{~min}$ and then analysed by using a Becton Dickinson FACSCalibur flow cytometer. Ten thousand cells were analysed for each sample. Cell cycle distribution was modelled using the ModFit LT software package (Verity Software House; Hedley et al. 1993).

Flow cytometric analysis of externalised phosphatidyl serine Externalisation of phosphatidyl serine (PS) on the outer membrane of promastigotes upon treatment with compound was determined by using annexin V-PE. Briefly, $2 \times 10^{6} \log$ phase $L$. donovani promastigotes overexpressing PTR1-GFP chimaera were incubated with compound $(98 \mu \mathrm{M}, 24 \mathrm{~h})$; cells were centrifuged at $2,000 \times \mathrm{g}$ for $5 \mathrm{~min}$ at $4^{\circ} \mathrm{C}$, washed twice in phosphate-buffered saline (0.02 M, pH7.2, PBS) and resuspended in annexin V-PE binding buffer (10 mM HEPES, $140 \mathrm{mM} \mathrm{NaCl}, 2.5 \mathrm{mM}$ $\mathrm{CaCl}_{2} ; \mathrm{pH} 7.4$ ). Annexin $\mathrm{V}-\mathrm{PE}$ was then added according to the manufacturer's instructions and incubated for $30 \mathrm{~min}$ in the dark at $20-25^{\circ} \mathrm{C}$. Acquisition was done on a FACSCalibur flow cytometer (BD) and analysed with CellQuest software.

Measurement of mitochondrial membrane potential Mitochondrial damage upon treatment with compound in $L$. donovani promastigotes overexpressing PTR1-GFP chimaera was assessed by flow cytometry using a cellpermeable dye, MitoTracker deep red. MitoTrackers are aldehyde fixable cationic lipophilic fluorochrome that passively diffuses through the plasma membrane of viable cells and is selectively sequestered in mitochondria with an active membrane potential and permits the examination of the membrane potential in adherent cells (Haugland 1996). L. donovani promastigotes were treated with compound (98 $\mu \mathrm{M}, 0-5 \mathrm{~h})$, washed in PBS and loaded in dark for 30 min with MitoTracker $(10 \mu \mathrm{M})$ as per the manufacturer's instructions (Molecular Probes). Analysis for mean fluorescence intensity was done using FACSCalibur and CellQuest software.

Analysis of nuclear morphology Oligonucleosomal fragmentation in L. donovani promastigotes (overexpressing PTR1-GFP chimaera) treated with the compound was identified microscopically using the fluorescent nucleic acid-specific stain PI. Briefly, promastigotes were incubated with compound $(98 \mu \mathrm{M} 0-48 \mathrm{~h})$, cells were then centrifuged at each time point, and the resultant pellet was loaded with PI $(10 \mu \mathrm{g} / \mathrm{ml})$ for $30 \mathrm{~min}$ at $20-25^{\circ} \mathrm{C}$, attached on poly-L-lysine coated glass slides, mounted in glycerol containing 1,4-diazabicyclo octane and examined under a confocal microscope (Leica, Germany). Untreated promastigotes at each corresponding time point were also processed and analysed similarly. At least 20 microscopic fields were observed for each sample.

Oligonucleosomal DNA fragmentation assay To analyse the presence of DNA fragments generated as a function of cell death, total cellular DNA from $L$. donovani promastigotes exposed to compound $(98 \mu \mathrm{M}, 0-48 \mathrm{~h})$ were isolated according to manufacturer's instructions (Bio-Rad). Extracted DNA was quantified spectrophotometrically by the absorbance ratio of $260 / 280 \mathrm{~nm}$, and DNA (10 $\mathrm{g} / \mathrm{lane})$ was separated by electrophoresis on $1 \%$ agarose gel containing ethidium bromide in Tris base-boric acid-EDTA buffer (50 mM; pH8.0) for $1.5 \mathrm{~h}$ at $75 \mathrm{~V}$, visualised under UV light and photographed using a gel documentation system (GelDoc 2000, Bio-Rad).

\section{Statistical analysis}

The data are presented as mean \pm SD. The statistical significance of differences in percentage between treated and untreated was analysed by one-way analysis of variance using GraphPad Prism software.

\section{Results}

Determination of cytotoxicity upon cells The toxicity data against host cell macrophages was gathered before testing the compound against the intracellular pathogen in vivo. Cytotoxic potential of compound at 30 and $100 \mu \mathrm{M}$ on 

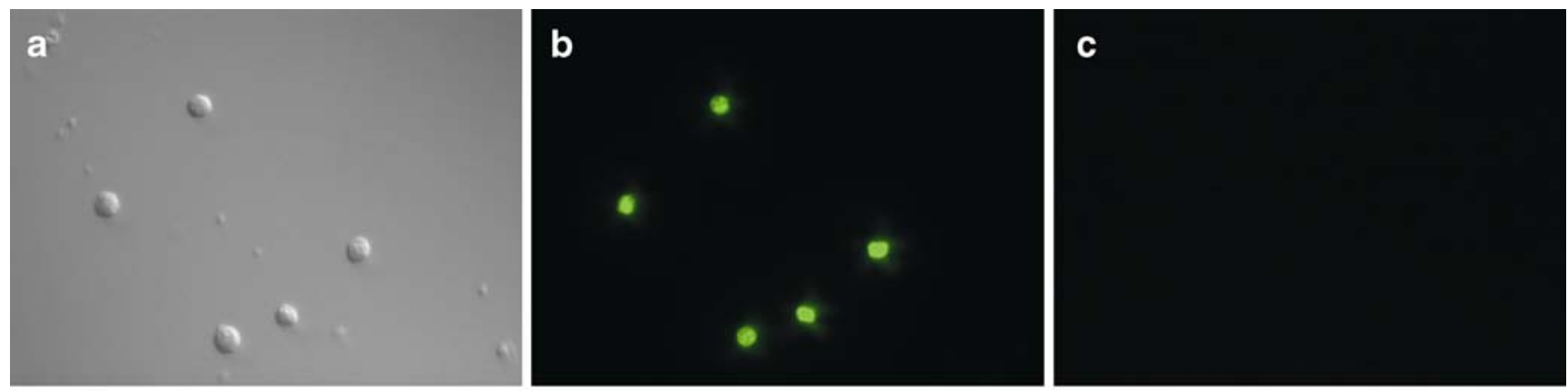

\section{Control}
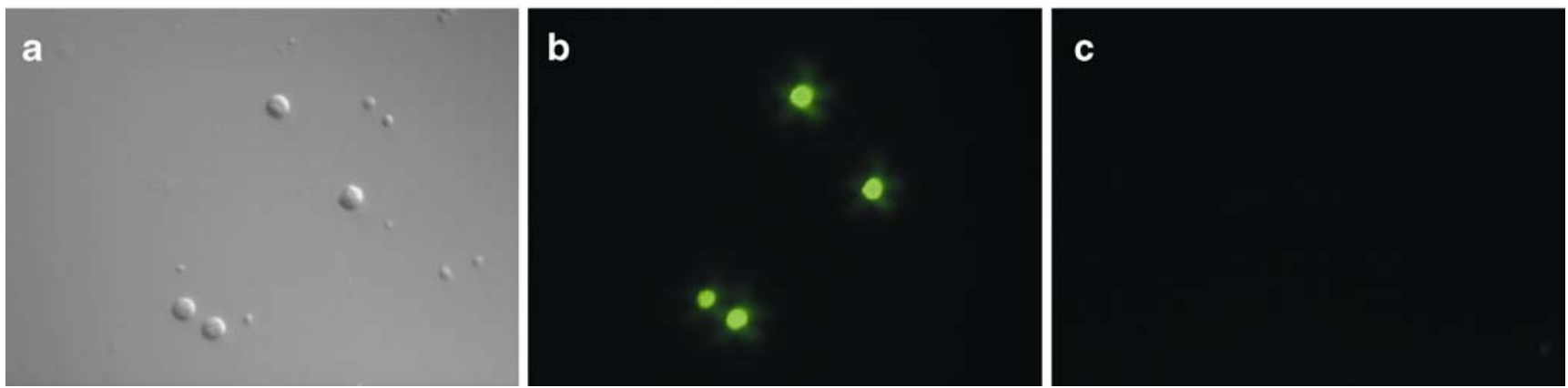

After $100 \mu \mathrm{M}$ of compound treatment

Fig. 2 Cytotoxicity assay on PBMCs from human peripheral blood; PBMCs were isolated from human peripheral blood. Cells were incubated with various concentrations of the compound. The mean percentage of post treatment viable cells relative to control was evaluated by epifluorescence microscopy (Leica) using Live-Dead Cell Staining Kit (BioVision). Magnification $\times 40$. a Differential

PBMC was determined. The compound showed no cytotoxicity against macrophages (Fig. 2). More importantly, absence of shared toxicity to PBMC has increased its therapeutic ratio.

Determination of the $I C_{50}$ of compound-mediated death in vivo The compound exhibited excellent in vivo antileishmanial efficacy by oral route against established infection of $L$. donovani. It imparted $80.4 \pm 2.4 \%$ inhibition of parasite at $50 \mathrm{mg} / \mathrm{kg}$ dose. At higher doses of 75 and $100 \mathrm{mg}$, it exhibited still higher $(85.7 \pm 5.4 \%$ and $93.5 \pm$ $4.5 \%$, respectively) growth inhibitory effect. $\mathrm{An} \mathrm{ED}_{50}$ of $36.3 \mathrm{mg} / \mathrm{kg}$ body weight was obtained (Fig. 3). This compound was devoid of any toxicity towards animals as no mortality was seen during the course of treatment.

Compound induces sub-G0/G1 phase cell cycle arrest in $L$. donovani promastigotes The least expensive and most rapid discrimination of apoptotic cells is based on DNA content analysis. This is an established approach for screening drug effects in vitro (Darzynkiewicz et al. 1997). The DNA content of cells is measured by the ability of PI to bind stoichiometrically to DNA under appropriate staining conditions. The nuclei of these stained cells are interference contrast image of isolated macrophages. b Live cells with green stain (flourescein isothiocyanate). c Dead cells with red stain (PI). As very low or no cells were dead, no red spots were found. Upper panels show the images without any treatment, and lower panels show the images after $100 \mu \mathrm{M}$ of compound treatment for $24 \mathrm{~h}$

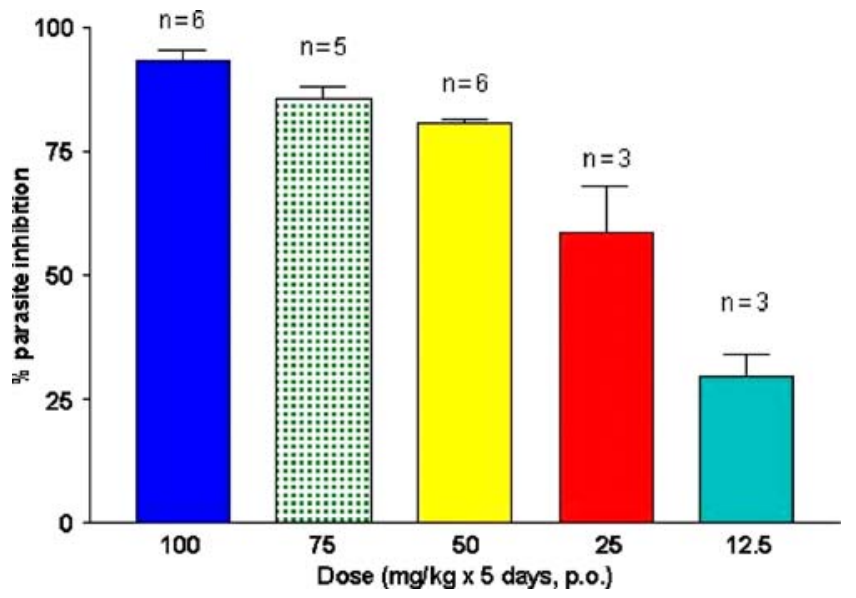

Fig. 3 Analysis of antileishmanial activity of compound in vivo. Syrian golden hamsters (M. auratus) were infected intracardially with $1 \times 10^{7}$ amastigotes isolated from the spleen of heavily infected donor hamsters. Animals were treated orally with the inhibitor at 12.5, 25, 50,75 and $100 \mathrm{mg} / \mathrm{kg}$ dose for five consecutive days. Splenic biopsies were performed on day 7 post treatment, and the parasite burden in treated and untreated groups were quantitated 
Fig. 4 DNA content (percent sub-G1) analysis of cells upon treatment with compound. Log phase $L$. donovani promastigotes (overexpressing PTR1GFP chimaera) were incubated with inhibitor $(98 \mu \mathrm{M})$ for 24 and $48 \mathrm{~h}$, stained with PI and analysed by flow cytometry. A significant sub-G1 was observed (blue). This is a representative profile of at least three experiments
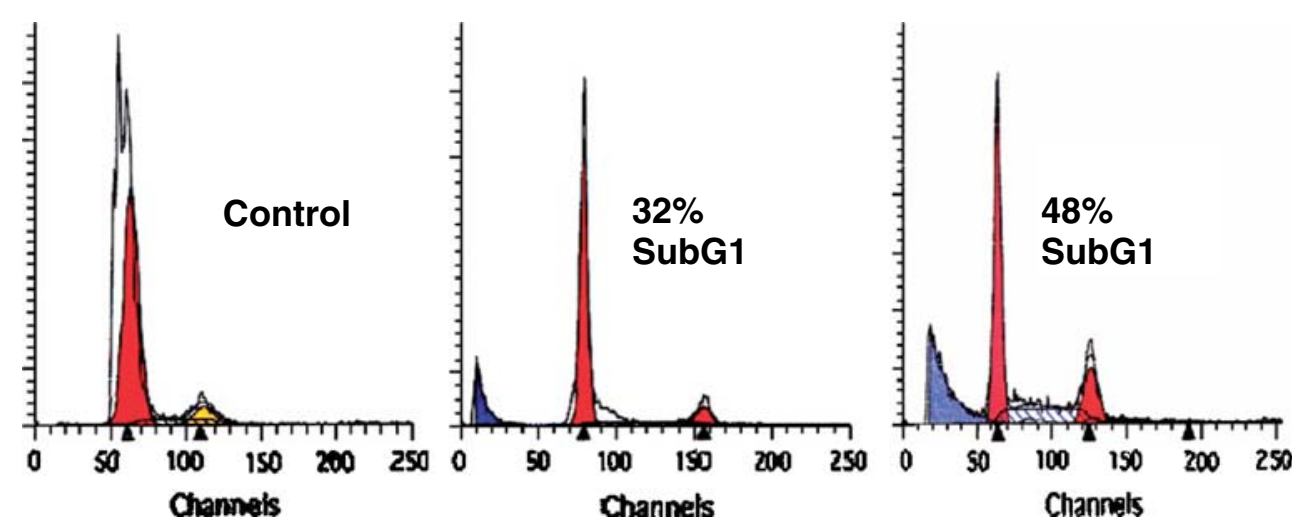

evaluated individually for DNA content by flow cytometry. The results are displayed graphically as a histogram in which the fluorescence emitted by each nucleus is directly proportional to its DNA content. In addition to the enumeration of apoptotic cells offered by this method, the cell cycle-specific effects can easily be recognised from DNA content histograms of the nonapoptotic cell populations. We performed a cell cycle analysis by flow cytometry after PI staining of the parasites incubated for $0-48 \mathrm{~h}$ at $\mathrm{IC}_{50}(98 \mu \mathrm{M})$ of the compound. To determine the apoptotic population, the sub-G0/G1 peak was measured. Figure 4 shows the DNA cell cycle histograms of parasites before and after treatment of the compound. DNA that is fragmented is observed in a sub-G1 peak in the DNA histograms of the treated parasites. The DNA histograms show that DNA fragments increased significantly in promastigotes from $24(32 \%)$ to $48 \mathrm{~h}(48 \%)$ compared to control. This suggests that this analogue could initiate late events of PCD such as nuclear condensation and DNA nicking.
L. donovani promastigotes show externalisation of phosphatidylserine following treatment with compound In metazoan and unicellular cells, ubiquitous alteration is the translocation of phosphatidylserine from the inner side to the outer layer of the plasma membrane during PCD (Mehta and Shaha 2004). Annexin V, a $\mathrm{Ca}^{2+}$-dependent phospholipid binding protein with affinity for phosphatidylserine, is routinely used to label externalisation of phosphatidylserine. Hence, for the determination of the mechanism of cell death triggered by this compound via apoptosis (annexin $\mathrm{V}$ positive), compound-treated $L$. donovani promastigotes overexpressing PTR1-GFP chimaera $(98 \mu \mathrm{M}, 24 \mathrm{~h})$ were stained with annexin V-PE. A significant percentage (46\%) of promastigotes of treated cells $(3 \mathrm{~h})$ stained positive for both GFP and annexin $\mathrm{V}$ as shown in upper right quadrant as compared to only $2.0 \%$ in untreated cells (Fig. 5). The percentage of double-stained cells (upper right quadrant) indicated that this inhibitor exerts its leishmanicidal activity primarily via apoptosis in Leishmania cells overexpressing PTR1. The increase in annexin $\mathrm{V}$ positive cells increased
Fig. 5 Externalisation of phosphatidylserine in L. donovani promastigotes overexpressing PTR1 upon treatment with compound. Log phase L. donovani promastigotes (overexpressing PTR1-GFP chimaera) were incubated with compound $(98 \mu \mathrm{M})$ for $24 \mathrm{~h}$, stained with annexin V-PE and analysed by flow cytometry. This is a representative profile of at least three experiments
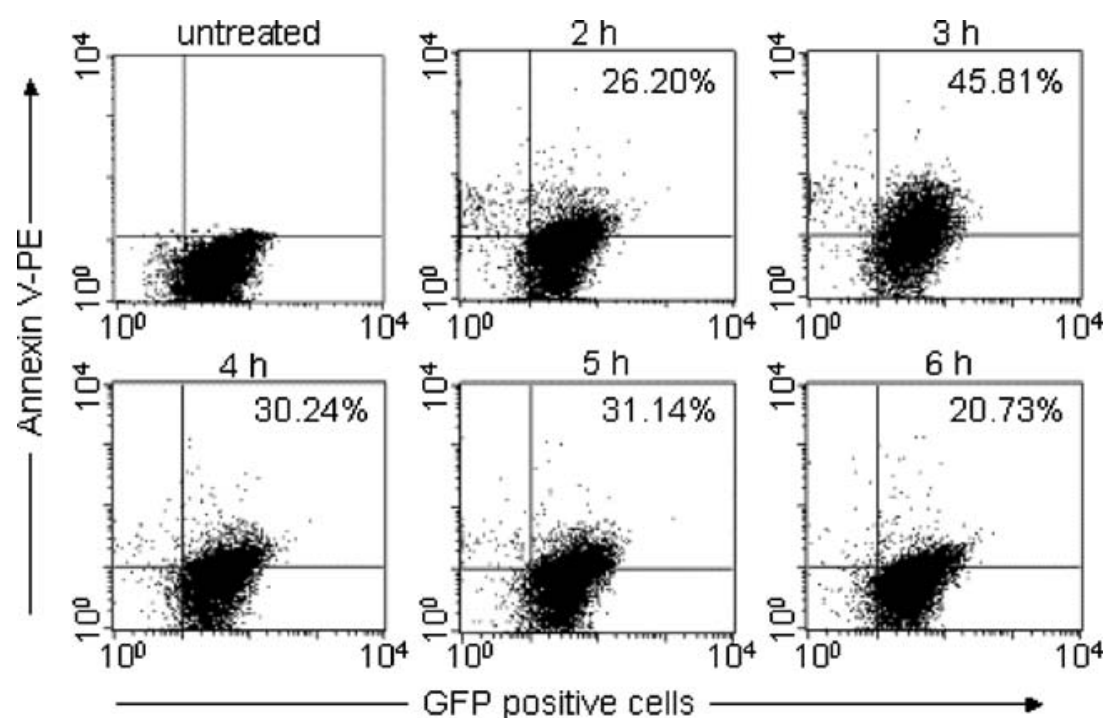
after $2 \mathrm{~h}$ of treatment, which reached maximum after $3 \mathrm{~h}$ and then decreased a bit. Most probably, decrease in plasma membrane integrity in treated cells is responsible for this.

Compound induces sustain depolarisation of mitochondrial membrane potential The loss of mitochondrial membrane potential is a characteristic feature of metazoan apoptosis and has been observed to play a key role in drug-induced death in protozoans such as Leishmania (Sen et al. 2004). L. donovani promastigotes overexpressing PTR1-GFP chimaera were treated with compound. Following treatment, membrane potential was determined by cytofluorometric measurement of the mitochondrial dependent uptake and retention of MitoTracker deep red (CMXRos) into mitochondria. CMXRos is an aldehyde fixable cationic lipophilic fluorochrome that passively diffuses through the plasma membrane of viable cells and is selectively sequestered in mitochondria with an active membrane potential and permits the examination of the membrane potential in cells (Haugland 1996; Shibayama-Imazu et al. 2006). PI staining was utilised to gate the necrotic cell population and debris from the viable cell population (Darzynkiewicz et al. 1997). Treatment with $98 \mu \mathrm{M}$ compound resulted in reduction of MitoTracker positive cells from $96.54 \%$ at $30 \mathrm{~min}$ to $9.86 \%$ in $5 \mathrm{~h}$ when compared to DMSO (0.25\%)-treated controls $(96.8 \%$; Fig. 6). A higher concentration of annexin $\mathrm{V}$ and MitoTracker were used to boost intracellular signalling.

Analysis of chromatin condensation in L. donovani promastigotes following treatment with compound During programmed cell death, the cleavage patterns of genomic DNA are typical of internucleosomal DNA digestion by endonucleases and are considered as a hallmark of apoptosis that is preceded by chromatin condensation and nuclear blebbing (Verma and Dey 2004). In untreated promastigotes (control) stained with PI, the cells appeared with discrete two red spots representing mitochondria and nucleus. In treated promastigotes $(24 \mathrm{~h}, 98 \mu \mathrm{M})$, the spot of mitochondria seems to be like the control cells, whereas the nuclear spot became discrete and appeared like blebbed nuclei. With increase in treatment time $(48 \mathrm{~h})$, promastigote morphology was totally altered. The shape became round and ovoid, the spot of the mitochondria abolished, indicating dyskinetoplastidy. More interestingly, the nucleus was represented by numerous spots indicating nuclear condensation (Fig. 7).

Oligonucleosomal DNA fragmentation analysis of L. donovani promastigotes following treatment with compound Analysis of integrity of genomic DNA (gDNA) by DNA laddering strengthened the claim that the compound induces active death process. A ladder-like pattern of oligonucleosomal DNA fragments was observed after $24 \mathrm{~h}$ of treatment (Fig. 8).

\section{Discussion}

We identified a potent inhibitor of $L$. donovani PTR1 from a collection of proprietary dihydropyrimidone (DHPM) derivatives with DHFR activity. Although PTR1 and DHFR are unrelated at the primary sequence level and structurally as well, both enzymes are inhibited by compounds containing the 2,4-diaminopyrimidine scaffold (Hardy et al. 1997). Recombinant enzyme inhibition as well as structure activity relationship established the high specific-
Fig. 6 Changes in mitochondrial membrane potential following treatment. Log phase L. donovani promastigotes (overexpressing PTR1-GFP chimaera) were incubated with compound $(98 \mu \mathrm{M})$ for $0-5 \mathrm{~h}$, loaded in dark for 30 min with MitoTracker $(10 \mu \mathrm{M})$ and analysed by flow cytometry. This is a representative profile of at least three experiments

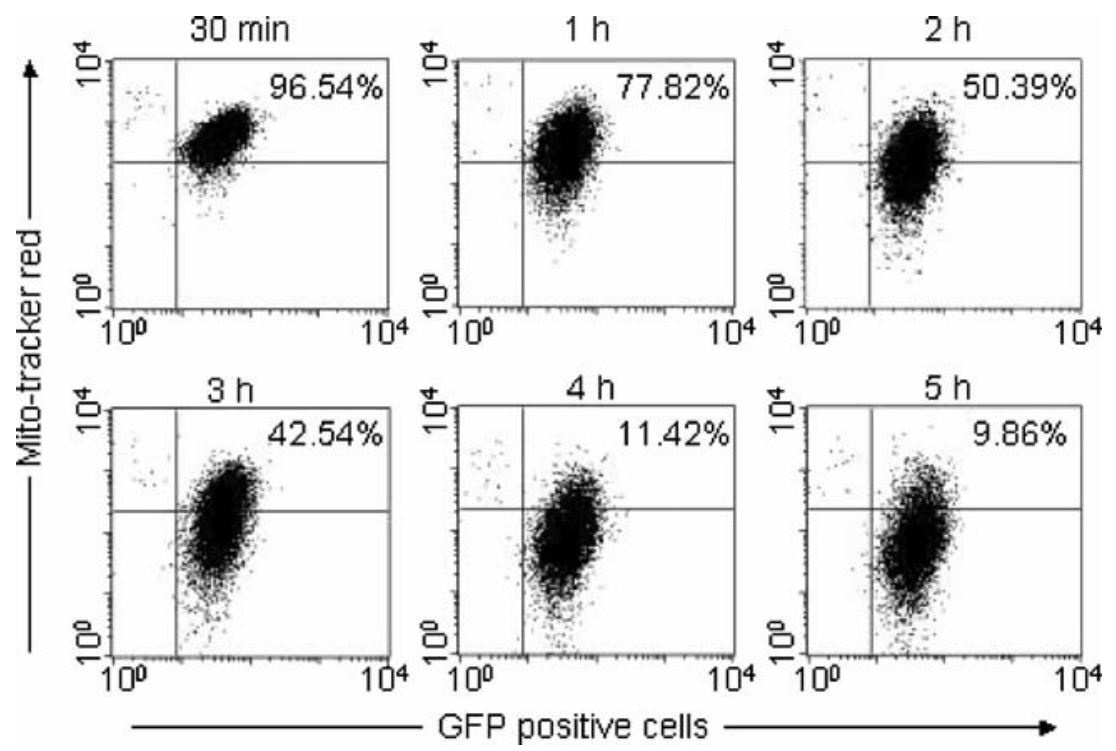



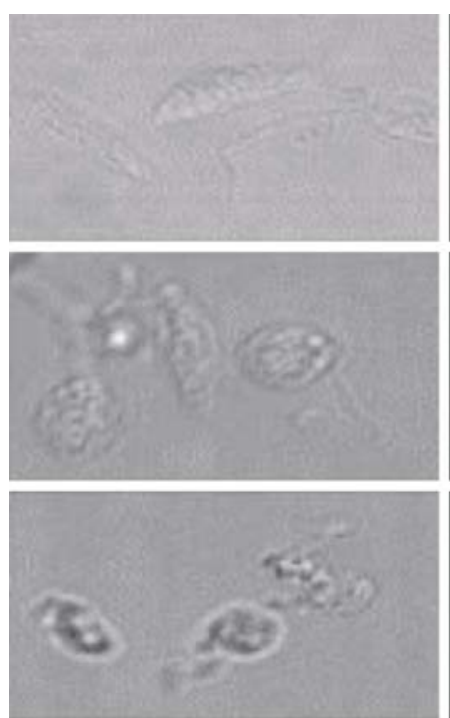

Phase
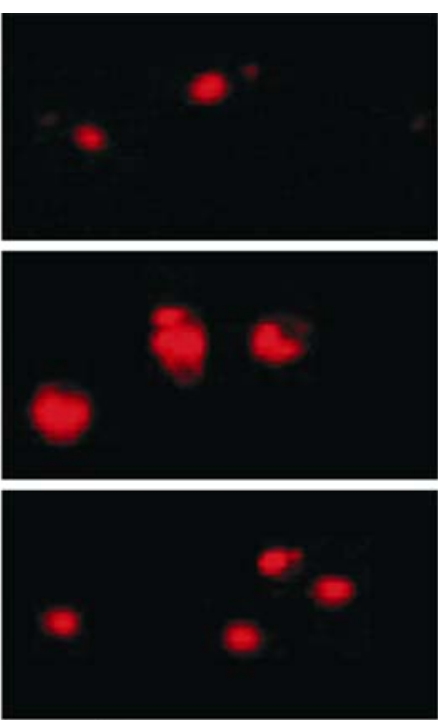

Fluorescence

Fig. 7 Analysis of nuclear morphology-oligonucleosomal fragmentation in L. donovani promastigotes (overexpressing PTR1-GFP chimaera) treated with the compound was identified microscopically using the fluorescent nucleic acid-specific stain propidium iodide. Log

ity towards the enzyme target by this compound. $\mathrm{IC}_{50}$ values determined on recombinant enzymes can be questionable. Thereby, intracellular amastigotes overexpressing PTR1 tagged at the N-terminal with GFP were used to establish the leishmanicidal activity in vitro in mouse macrophages (Green Screen Assay). Using this system, we obtained an $\mathrm{IC}_{50}$ of $23 \mu \mathrm{M}$ in amastigotes. Our study thus demonstrates the utility of cell-based assays using gene overexpression as a useful chemical genetic screening system targeting both genotoxic and cytotoxic events within the cell. This compound showed a high therapeutic index in vivo and can give $\sim 93 \%$ decreases in parasite burden in $L$. donovani-infected hamsters. This dosage eliminated $\sim 93 \%$ of parasites (i.e. that was essentially curative) and did not also result in $>10 \%$ mean weight loss, which we arbitrarily chose as an indication of drug toxicity. The nonspecific toxicity against host cells highlights the important relationship between structure and biological selectivity of compounds. The compound showed leishmanicidal effect on $L$. donovani promastigotes which was enhanced on intracellular organisms both in vitro and in vivo model, suggesting that interaction of the compound with host cell or with cellular events is important for its inhibitory effect. The efficacy of this inhibitor is due to excellent cell permeability. Our molecule resembles monastrol, a structurally rather simple DHPM, which is the only cell-permeable molecule currently considered as a lead for the development of new anticancer drug (Kapoor et al. 2000). This compound exhibited superior oral antileishma-
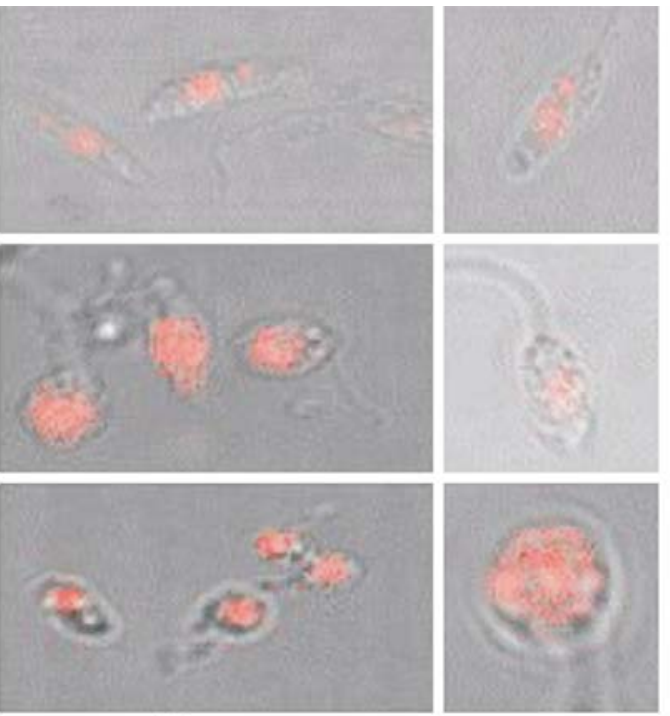

Control

Merge

phase promastigotes were incubated with compound $(98 \mu \mathrm{M})$ for 24 and $48 \mathrm{~h}$, respectively, adhered on poly-L-lysine coated cover slips and analysed under confocal microscope. Magnification $\times 40$. Images are representative of one of three similar results

nicidal activity. Orally active long-lasting antihypertensive agents of DHPM specificity have been reported (Wang et al. 2006) resulting from the increased chemical stability of the urea functionality. Because of the pharmacological potency of the DHPM scaffold, dihydropyrimidines with important biological properties have been cited (Darzynkiewicz et al. 1997; Hardy et al. 1997; Haugland 1996; Green and Kroemer 1998; Gottlieb 2000). The heterocyclic scaffold of this compound is found in natural marine alkaloid

Fig. 8 Time course of DNA fragmentation observed following treatment with compound. gDNA $(10 \mu \mathrm{g})$ isolated from $L$. donovani promastigotes, which have been treated with compound $(98 \mu \mathrm{M})$ for $24 \mathrm{~h}$ and $48 \mathrm{~h}$, were resolved on $1 \%$ agarose gel. First lane positive control consisting of lyophilised apoptotic cells, second lane negative control consisting of cells without any treatment, third lane $24 \mathrm{~h}$ of compound treatment, fourth lane, $48 \mathrm{~h}$ of compound treatment

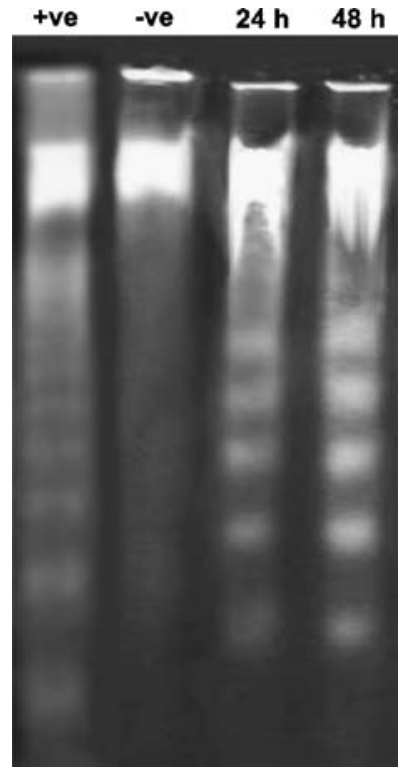


batzalladines (Patil et al. 1995). Efforts are directed against getting the biologically active natural product. Having established the leishmanicidal effect of compound on $L$. donovani in promastigotes and amastigotes, we sought to establish the type of death caused by this compound. On treatment of $L$. donovani promastigotes with compound, sub-G1 peak characteristic of apoptosis occurred at $24 \mathrm{~h}$. Different apoptosis markers, such as externalisation of PS and nuclear DNA fragmentation, were observed in $24 \mathrm{~h}$. The induction of mitochondrial dysfunction in the apoptotic process was apparent in the MitoTracker Red study results. The study of mitochondrial potential has become a focus of apoptosis regulation as many investigations demonstrate a major functional impact of mitochondrial alterations on apoptosis (Gottlieb 2000). Many antileishmanial drugs (Sen et al. 2004; Scarlett et al. 2000; Sudhandiran and Shaha 2003; Santa-Rita et al. 2006) cause a significant fall in membrane potential (Haugland 1996). In higher eukaryotic cells, apoptosis often occurs downstream of the death signal by protease activation, leading to endonuclease ignition (Green and Kroemer 1998). In these instances, cysteine proteases of the caspase family, $\mathrm{Ca}^{2+}$-sensitive calpains or proteasomes can initiate cell death. We are tempted to speculate that release of death factors from mitochondria of promastigotes overexpressing PTR1 as a result of treatment with compound is causing apoptosis without involving caspases. This analogy is based on our earlier confirmation that degradation of the PTR1 protein is not by the usual multivesicular tubule lysosome pathway but is mediated by the proteasome (Kumar et al. 2007). Existence of a caspaseindependent apoptotic pathway to antimonial drugs, in Leishmania, has been reported (Holzmuller et al. 2002; Lee et al. 2002; Sereno et al. 2001). There is a general consensus that DNA is the main target for most, if not all, apoptotic drugs. In the present study, we found that compound-induced cell death was accompanied by dyskinetoplastidy, i.e. loss of kDNA network, and was associated with extensive nuclear DNA fragmentation. This endonuclease activity could be due to a coordinated process of intracellular protein degradation mediated by the proteasome, leading to nuclear DNA fragmentation. In conclusion, on screening DHPM derivatives with DHFR specificity, we have identified a lead compound with remarkable in vivo activity. The interaction of this compound with its biological target viz. PTR1 at the molecular level has been affirmed.

Acknowledgement We are grateful to the Department of Biotechnology, India (grant no. BT/PR5452/BRB/10/430/2004) for financial assistance for this study.

Open Access This article is distributed under the terms of the Creative Commons Attribution Noncommercial License which permits any noncommercial use, distribution, and reproduction in any medium, provided the original author(s) and source are credited.

\section{References}

Atwal KS, Swanson BN, Unger SE, Floyd DM, Moreland S, Hedberg A, O'Reilly BC (1991) Dihydropyrimidine calcium channel blockers. 3-Carbamoyl-4-aryl-1,2,3,4-tetrahydro-6-methyl-5pyrimidinecarboxylic acid esters as orally effective antihypertensive agents. J Med Chem 34:806-811

Bello AR, Nare B, Freedman D, Hardy L, Beverley SM (1994) PTR1: a reductase mediating salvage of oxidized pteridines and methotrexate resistance in the protozoan parasite Leishmania major. Proc Natl Acad Sci 91:11442-11446

Berman J, Bryceson ADM, Croft S, Engel J, Gutteridge W, Karbwang J, Sindermann H, Soto J, Sundar S, Urbina JA (2006) Miltefosine: issues to be addressed in the future. Trans $\mathrm{R}$ Soc Trop Med Hyg 100(Suppl 1):S41-S44

Darzynkiewicz Z, Juan G, Li X et al (1997) Cytometry in cell necrobiology: analysis of apoptosis and accidental cell death (necrosis). Cytometry 27:1-20

Dwivedi N, Mishra RC, Tripathi RP (2005) Tetrabutylammonium hydrogensulphate catalysed efficient synthesis of glycosyl (aryl) dihydropyrimidinones. Lett Org Chem 5:450-457

Fuss IJ, Kanof ME, Smith PD, Zola H (2009) Isolation of whole mononuclear cells from peripheral blood and cord blood. Curr Protoc Immunol Chapter 7:Unit7.1

Gottlieb RA (2000) Role of mitochondria in apoptosis. Crit Rev Eukaryot Gene Expr 10:231-239

Green D, Kroemer G (1998) The central executioners of apoptosis: caspases or mitochondria? Trends Cell Biol 8:267-271

Hardy LW, Matthews W, Nare B, Beverly SM (1997) Biochemical and genetic tests for inhibitors of Leishmania pteridine pathways. Exp Parasitol 87:157-169

Haugland RP (1996) Handbook of fluorescent probes and research chemicals. Molecular Probes, Eugene

Hedley DW, Shankey TV, Wheeless LL (1993) DNA cytometry consensus conference. Cytometry 14:471-500

Holzmuller P, Sereno D, Cavaleyra M, Mangot I, Daulouede S, Vincendeau P, Lemesre JL (2002) Nitric oxide-mediated proteasome-dependent oligonucleosomal DNA fragmentation in Leishmania amazonensis amastigotes. Infect Immum 70(7):3727-3735

Kapoor T, Mayer TU, Coughlin ML, Mitchison TJ (2000) Probing Spindle assembly mechanisms with monastrol, a small molecule inhibitor of the mitotic kinesin, Eg5. J Cell Biol 150:975-988

Kappe CO (1993) 100 Years of the Biginelli dihydropyridines synthesis. Tetrahedron 49:6937

Kappe CO (2000) Biologically active dihydropyrimidones of the Biginelli-type, a literature survey. Eur J Med Chem 35:1043-1052

Kappe CO, Fabian WMF, Semones MA (1997) Conformational analysis of 4-aryl-dihydropyrimidine calcium channel modulators. A comparison of ab initio, semi empirical and X-ray crystallographic studies. Tetrahedron 53:2803

Küçükgüzel I, Tatar E, Küçükgüzel SG, Rollas S, De Clercq E (2007) Synthesis of some novel thiourea derivatives obtained from 5-[(4aminophenoxy) methyl]-4-alkyl/aryl-2,4-dihydro-3H-1,2,4-triazole3 -thiones and evaluation as antiviral/anti-HIV and antituberculosis agents. Eur J Med Chem 43:381-392

Kumar P, Sundar S, Singh N (2007) Degradation of pteridine reductase 1 (PTR1) enzyme during growth phase in the protozoan parasite Leishmania donovani. Exp Parasitol 116:182-189

Kumar P, Kumar A, Verma SS, Dwivedi N, Singh N, Siddiqi MI, Tripathi RP, Dube A, Singh N (2008) Leishmania donovani pteridine reductase 1: biochemical properties and structure modeling studies. Exp Parasitol 120:73-79

Lee N, Bertholet S, Debrabant A, Muller J, Duncan R, Nakhasi HL (2002) Programmed cell death in the unicellular protozoan parasite Leishmania. Cell Death Differ 9:53-64 
Mann KK, Davison K, Colombo M, Colosimo AL, Diaz Z, Padovani AMS, Guo Q, Scrivens PJ, Gao WJ, Mader S, Miller WH (2006) Antimony trioxide-induced apoptosis is dependent on SEK1/JNK signaling. Toxicol Lett 160:158-170

Mehta A, Shaha C (2004) Apoptotic death in Leishmania donovani promastigotes in response to respiratory chain inhibition: complex II inhibition results in increased pentamidine cytotoxicity. J Biol Chem 279:11798-11813

Patil AD, Kumar NV, Kokke WC, Bean MF, Freyer AJ, Debrossi C, Mai S, Truneh A, Faulkner DJ, Carte B, Breen AL, Hertzberg RK, Johnson RK, Westley JW, Potts BCM (1995) Novel alkaloids from the sponge Batzella sp.: inhibitors of HIV gp120-human CD4 binding. J Org Chem 60:1182-1188

Santa-Rita RM, Barbosa HS, De Castro SL (2006) Ultrastructural analysis of edelfosine-treated trypomastigotes and amastigotes of Trypanosoma cruzi. Parasitology Res 100:187-190

Scarlett JL, Sheard PW, HughesG LEC, Ku HH, Murphy MP (2000) Changes in mitochondrial membrane potential during staurosporineinduced apoptosis in Jurkat cells. FEBS Lett 475:267-272

Sen N, Das BB, Ganguly A, Mukherjee T, Tripathi G, Bandyopadhyay S, Rakshit S, Sen T, Majumder HK (2004) Camptothecin induced mitochondrial dysfunction leading to programmed cell death in unicellular hemoflagellate. Leishmania donovani. Cell Death Differ 11:924-936

Sereno DP, Holzmuller I, Mangot G, Cuny A, Ouaissi J, Lemesre L (2001) Antimonial-mediated DNA fragmentation in Leishmania infantum amastigotes. Antimicrob Agents Chemother 45:2064ss-2069ss
Shaha C (2006) Apoptosis in Leishmania species and its relevance to disease pathogenesis. Ind J Med Res 123:233-244

Shibayama-Imazu T, Sonoda I, Sakairi S, Aiuchi T, Ann WW, Nakajo S, Itabe H, Nakaya K (2006) Production of superoxide and dissipation of mitochondrial transmembrane potential by vitamin $\mathrm{K} 2$ trigger apoptosis in human ovarian cancer TYK-nu 520 cells. Apoptosis 11:1535-1543

Singh N, Dube A (2004) Fluorescent Leishmania: application to antileishmanial drug testing. Am J Trop Med Hyg 71:400-402

Singh G, Jayanarayan KG, Dey CS (2005) Novobiocin induces apoptosis-like cell death in topoisomerase II over-expressing arsenate resistant Leishmania donovani. Mol Biochem Parasitol 141:57-69

Sudhandiran G, Shaha C (2003) Antimonial induced increase in intracellular $\mathrm{Ca}^{2+}$ through non-selective cation channels in the host and the parasite is responsible for apoptosis of intracellular Leishmania donovani amastigotes. J Biol Chem 278:2512025132

Sundar S, Chatterjee M (2006) Visceral leishmaniasis-current therapeutic modalities. Indian J Med Res 23:345-352

Verma NK, Dey CS (2004) Possible mechanism of miltefosine mediated death of Leishmania donovani. Antimicrob Agents Chemother 48:3010-3015

Wang X, Quan Z, Wang JK, Zhang Z, Wang M (2006) A practical and green approach toward synthesis of N3-substituted dihydropyrimidinones: using Aza-Michael addition reaction catalyzed by $\mathrm{KF} / \mathrm{Al}_{2} \mathrm{O}_{3}$. Bioorg Med Chem Lett 16:4592-4595 